\title{
Minimally Invasive Biopsy Methods - Diagnostics or Therapy? Personal Opinion and Review of the Literature
}

\author{
Ute Kettritz
}

Referenzzentrum Mammographie Berlin, Germany

\author{
Keywords \\ Minimally invasive biopsy - Vacuum-assisted biopsy . \\ Core needle biopsy
}

\section{Summary}

This article provides an overview of different minimally invasive biopsy (MIB) methods for preoperative assessment of suspicious and indeterminate breast lesions. Accuracy depends on the choice of method and on lesion characteristics. An additional aspect deals with the question whether or not MIB is a suitable therapeutic approach in selected lesions.

\section{Introduction}

Minimally invasive biopsy (MIB) has replaced open excisional biopsy in patients with imaging-detected suspicious or indeterminate breast lesions. Compared to surgical excision, MIB has the same or even better precision, decreases the psychological burden affecting the patients, and reduces costs [1-3]. MIB decreases the number of surgical procedures required in patients with impalpable breast cancer compared to diagnostic open surgery $[1,2,4]$.

\section{MIB in the Multidisciplinary Setting}

The accuracy of MIB depends on the lesion, the choice of biopsy device, and the radiological-pathological correlation. Therefore, interdisciplinary teamwork is mandatory in this field. Helpful in the communication between the radiologist and the pathologist are the Breast Imaging Reporting and Data System (BI-RADS) classification and the B-categorization. BI-RADS was established by the American College of Radiology to standardize radiological terms and reports [5]. It provides diagnostic categories that have implications for guidance regarding follow-up or biopsy of imaging-detected breast lesions. Further assessment with MIB is indicated for

\author{
Schlüsselwörter \\ Minimal-invasive Biopsie $\cdot$ Vakuumbiopsie $\cdot$ Corebiopsie
}

\section{Zusammenfassung}

Die vorliegende Arbeit gibt einen Überblick über die verschiedenen Methoden der minimal-invasiven Biopsie (MIB) zur Klärung von unklaren und verdächtigen bildgebenden Befunden der Mamma. Voraussetzung für eine hohe Treffsicherheit ist die Wahl der geeigneten Methode in Abhängigkeit vom bildgebenden Befund. Ein weiterer Aspekt beschäftigt sich mit der Frage, ob einzelne minimal-invasive Verfahren auch für einen therapeutischen Ansatz in Frage kommen.

all imaging findings categorized as BI-RADS 4 (suspicious of malignancy) and BI-RADS 5 (highly suspicious of malignancy). To provide quality assurance in the pathological assessment in MIB of non-palpable lesions, European guidelines recommend a pathology classification scheme that includes 5 reporting categories, the so-called B-categorization (table 1) [6, 7]. Both classifications have given an important tool to radiologists and pathologists to work towards optimal patient management.

\section{Accuracy of the Different MIB Methods}

Both an appropriate imaging modality and an appropriate biopsy device have to be selected by the radiologist. Current techniques that are available include fine-needle aspiration (FNA), core-needle biopsy (CNB), and vacuum-assisted biopsy (VAB).

\section{Fine-Needle Aspiration}

The reported sensitivity and specificity of FNA varies considerably. The frequency of insufficient samples ranges from 8.5$46 \%[8,9]$. Main disadvantages of FNA include unreliability of hormone receptor status assessment and the lack of distinction between invasive and non-invasive tumors in many cases.

\section{KARGER \\ Fax +497614520714 \\ Information@Karger.de}

www.karger.com (c) 2011 S. Karger GmbH, Freiburg

$1661-3791 / 11 / 0062-0094 \$ 38.00 / 0$

Accessible online at:

www.karger.com/brc
PD Dr. Ute Kettritz

Referenzzentrum Mammographie Berli

Strasse des 17. Juni 106-108

10623 Berlin, Germany

u.kettritz@referenzzentrum-berlin.de 
Table 1. Reporting categories of needle biopsies (B-classification), according to the EC Working Group on Breast Screening Pathology [6]

\begin{tabular}{ll}
\hline Category & Terminology \\
\hline B1 & normal tissue or uninterpretable \\
B2 & benign (usual ductal hyperplasia, sclerosing adenosis, fibroadenoma, involutionary calcification, periductal mastitis, hamartoma) \\
B3 & benign but of uncertain biological potential (papillomas, radial scar, lobular intraepithelial neoplasia, atypical epithelial proliferation of \\
ductal type (AEDT), phylloides tumor) \\
B4 & suspicious (changes suggestive of in situ or invasive malignancy) \\
& malignant \\
& a) in situ \\
b) invasive & c) uncertain whether in situ or invasive \\
d) other malignancies
\end{tabular}

In benign results, FNA is not able to reliably confirm the benign nature of calcifications. Because of these problems, there is no role for this method in the assessment of breast lesions $[8,10]$.

\section{Core Needle Biopsy}

CNB allows a tissue cylinder to be excised. Histopathological diagnoses including prognostic criteria such as tumor grading and hormone receptor status can be provided. When 14-gauge needles are employed, a sensitivity of $85-97 \%$ and a specificity of $100 \%$ have been reported $[8,11-14]$. The accuracy is higher in non-calcified lesions. In assessing solely microcalcifications, CNB has limitations that need to be recognized. $\mathrm{CNB}$ may miss microcalcifications because the lesion is not reliably sampled. The failure of CNB to spare the patient a surgical procedure is higher for calcifications than for masses $[15,16]$. A further limitation is incomplete characterization of disease extent within the samples that may lead to underestimation of disease. Underestimation occurs most commonly in lesions presenting as microcalcifications or architectural distortions. A diagnosis of atypical ductal hyperplasia (ADH) in $\mathrm{CNB}$ results in an upgrade to ductal carcinoma in situ (DCIS) or invasive carcinoma during open surgery in up to $56 \%[15,17-$ 19]. DCIS, when diagnosed with CNB, is upgraded to invasive carcinoma during surgery in up to $50 \%[17,19,20]$. Thus, regarding the higher accuracy of CNB in non-calcified lesions, the method is the standard diagnostic procedure in assessing masses and is commonly used under ultrasound guidance. In microcalcifications suggestive of DCIS, stereotactic VAB has recognized advantages and should be the preferred method. CNB is associated with low morbidity and complication rates and low equipment costs. Precise BI-RADS categorization before biopsy and the use of the appropriate technical equipment (linear transducer with at least $7 \mathrm{MHz}$ ) are preconditions for reaching reliable results $[12,14]$.

Vacuum-Assisted Biopsy

$\mathrm{VAB}$ was introduced to circumvent limitations of CNB [21]. $\mathrm{VAB}$ removes a greater tissue volume and minimizes sampling error $[19,21]$. When targeting microcalcifications with MIB, removal of calcification-containing tissue is mandatory to allow a reliable histopathological diagnosis [22, 23]. For subsequent operative planning, the histological differen- tiation between invasive carcinoma, DCIS, and ADH is of major significance. Despite the relatively large biopsy specimen, VAB cannot completely avoid the problem of tumor upgrade in the surgical specimen. Nevertheless, several studies documented the higher precision of VAB compared to CNB. $\mathrm{VAB}$ reduced the probability of a subsequent upgrade in the surgical specimen by at least half compared to CNB $[15,19]$. Stereotactic VAB has been established as the procedure of choice in assessing indeterminate and suspicious microcalcifications graded as BI-RADS 4. These lesions are associated with a malignancy rate of $20-35 \%$ [24, 25].

Several studies have documented efficiency and safety of VAB [15, 19, 26, 27]. A standardized procedure and close cooperation between radiologist and pathologist assure the utility of the method [28]. Close communication between the radiologist and the pathologist must deal with the size and morphology of the calcifications documented on the specimen radiograph. If no calcifications are visible in the biopsy specimens and the histological diagnosis is classified as benign, a sampling error may nonetheless have occurred, diminishing the reliability of the diagnosis [16]. VAB may also be used under ultrasound and magnetic resonance (MR) guidance. In ultrasound-guided biopsies, the accuracy of CNB is similar to the accuracy of VAB. Therefore, CNB is chosen most commonly. However, VAB might have advantages in selected difficult cases, such as complex cysts or small unspecific lesions without criteria of malignancy [29]. Precise ultrasound classification according to the BI-RADS categories before biopsy and the use of the appropriate technical equipment are necessary to reach reliable results [29]. VAB, when performed under MR guidance, is a reliable method in the assessment of suspicious lesions visible only on magnetic resonance imaging (MRI) [30, 31].

\section{Biopsy as a Therapeutic Option?}

\begin{abstract}
Benign Lesions
A benign diagnosis following $\mathrm{CNB}$ or $\mathrm{VAB}$ is reliable if the diagnostic procedure is done in a standardized fashion and radiological-pathological correlation is provided in an interdisciplinary setting. Therefore, patients with a benign his-
\end{abstract}


topathological diagnosis can be spared the surgical removal of the lesion, especially in asymptomatic lesions. Nevertheless, on occasion, patients may warrant complete excision of the lesion. Since VAB gives the opportunity to remove relatively large tissue amounts, it can be used to excise small lesions as an alternative to open surgery for women with a known benign mass, who desire excision but prefer to avoid surgery or who are not suitable for surgery. VAB is well tolerated [32]. Thurley et al. [33] performed ultrasound-guided VAB in 134 patients with benign lesions. In $96 \%$ of the patients, the lesion was removed completely as assessed by ultrasound during the procedure. The procedure might be a save option in small fibroadenomas or complex cystic lesions without suggestion of malignant disease [29].

\section{Malignant Lesions}

The goal of surgical management in malignant lesions is the complete removal of invasive carcinoma and/or DCIS with clear margins. CNB and VAB are not suitable in this setting and are not recommended as a therapeutic option in malignant disease. Even after complete removal of small microcalcification areas by VAB and the diagnosis of DCIS, surgical excision of the area is mandatory to assure clear margins. Importantly, Penco et al. [34] demonstrated residual cancer at surgery in $87 \%$ of $1,016 \mathrm{VAB}$ procedures with malignant preoperative histopathology. After complete removal of microcalcifications by $\mathrm{VAB}$, the rate of residual malignancy at surgery was still as high as $70 \%$.

In an attempt to avoid open surgery, different percutaneous excisional devices were developed with the goal to allow complete removal of small malignant lesions. The Advanced Breast Biopsy Instrumentation (ABBI ${ }^{\mathrm{TM}}$; United States Surgical Corp., Norwalk, CT, USA) and SiteSelect ${ }^{\text {TM }}$ (SiteSelect Medical Technologies Ltd., Edinburg, TX, USA) devices were manufactured to allow the excision of a whole tissue cylinder. More recently, devices with the utilization of radiofrequency energy have become available [35]. Due to a very high rate of positive margins and the higher complication rate compared to $\mathrm{VAB}$, these tools are however currently not used as standard procedures [10,36, 37].

\section{Lesions with Uncertain Biological Potential (B3)}

With the widespread use of MIB in non-palpable lesions frequently detected in mammography screening, B3 lesions are more often diagnosed than in the prescreening era. Lesions included in this group are atypical epithelial proliferations, lobular neoplasia, phylloides tumor, papillary lesions, and radial scars. Management of B3 lesions remains a challenge for the multidisciplinary team. While the majority of women with a B3 diagnosis will have benign findings after surgical excision, some will have a malignancy associated with the B3 lesion which was insufficiently sampled by MIB. The likelihood of malignancy following a B3 biopsy result varies widely according to the lesion type. The standard approach is the surgical removal of the lesion and subsequent histological assessment. In an attempt to avoid unnecessary surgery in non-malignant lesions, some groups try to increase the diagnostic yield by performing additional VAB after MIB diagnosis of B3. The success of such an approach depends on the lesion type.

In $\mathrm{ADH}$, most authors recommend surgical excision, because upgrade at surgery reaches $45 \%[38,39]$. No significant difference was found using VAB with larger needle size [39]. Recently, Kohr et al. [40] found an upgrade at surgery in $20 \%$ of patients with ADH. Underestimation in MIB was higher when $\mathrm{ADH}$ involved at least 3 foci. The authors defined a subgroup where the microcalcification area was completely removed by VAB. This subgroup was characterized by ADH involving less than 3 foci. Upgrade to DCIS or invasive carcinoma was still $12 \%$. Thus, the authors recommend surgical excision in all ADH lesions.

$\mathrm{VAB}$ as a minimally invasive alternative to open surgery was studied in other B3 lesions found via CNB or VAB. Papillary lesions without atypia have a low likelihood of malignancy at surgery. Some authors suggest VAB as an alternative treatment to open surgery in small single papillomas without atypia found upon MIB. However, careful case selection and the goal of complete lesion removal are important [41-43].

Radial scars on MIB warrant surgical excision because of frequently associated malignancies. Some authors recommend VAB as an alternative to open excision in the management of radial scars without atypia in MIB. In some studies, the rate of malignancy detected in open surgery after radial scar diagnosis via VAB was very low [44, 45]. Recently, Rajan et al. [46] showed confirmation of radial scars without atypia in 11/14 patients undergoing VAB after an initial diagnosis of non-atypical radial scar. The question whether or not VAB can be recommended as a treatment option in small radial scars without atypia is still under discussion [47].

\section{Conclusion}

$\mathrm{CNB}$ and $\mathrm{VAB}$ provide high accuracy in assessing suspicious and indeterminate lesions. In benign lesions, MIB can prevent surgery. In malignant lesions, exact preoperative assessment of the extent and characteristics of the lesion assures optimal and individualized treatment. $\mathrm{VAB}$ and $\mathrm{CNB}$ are standard procedures to assure this goal. Success depends on the right choice of MIB method, a standardized performance, and radiological-pathological correlation on a regular basis. There is limited relevance for MIB as a therapeutic approach in selected benign lesions and selected small non-atypical B3 lesions.

\section{Disclosure Statement}

The author declares no conflict of interest.
96

Breast Care 2011;6:94-97
Kettritz 


\section{References}

1 Yim JH, Barton P, Weber B, Radford D, Levy J, Monsees B, Flanagan F, Norton JA, Doherty GM: Mammographically detected breast cancer. Benefits of stereotactic core versus wire localization biopsy. Ann Surg 1996;223:688-697; discussion 697-700.

-2 Liberman L, LaTrenta LR, Dershaw DD, Abramson AF, Morris EA, Cohen MA, Rosen PP, Borgen PI: Impact of core biopsy on the surgical management of impalpable breast cancer. AJR 1997;168:495-499.

3 Gundry KR, Berg WA: Treatment issues and core needle breast biopsy: clinical context. AJR 1998;171:41-49.

${ }_{4}$ Verkooijen HM, Borel Rinkes IH, Peeters PH, Landheer ML, van Es NJ, Mali WP, Klinkenbijl $\mathrm{JH}$, van Vroonhoven TJ: Impact of stereotactic large-core needle biopsy on diagnosis and surgical treatment of nonpalpable breast cancer. Eur J Surg Oncol 2001;27:244-249.

5 ACR Breast Imaging Reporting and Data System Atlas (BI-RADS Atlas). Reston, VA, American College of Radiology, 2003.

6 Perry N, Broeders M, de Wolf C, Törnberg S, Holland R, von Karsa L: European Guidelines for Quality Assurance in Breast Cancer Screening and Diagnosis. Luxembourg, Office for Official Publications of the European Communities, 2006.

7 Kluttig A, Trocchi P, Heinig A, Holzhausen HJ, Taege C, Hauptmann S, Boecker W, Decker T, Loening T, Schmidt-Pokrzywniak A, Thomssen C, Lantzsch T, Buchmann J, Stang A: Reliability and validity of needle biopsy evaluation of breastabnormalities using the B-categorization - design and objectives of the Diagnosis Optimisation Study (DIOS). BMC Cancer 2007;7:100.

8 Newman MR, Frost FA, Sterrett GF, Bourke AG, Thompson RI, Hastrich DJ, Ingram DM: Diagnosis of breast microcalcifications: a comparison of stereotactic FNA and core imprint cytology as adjuncts to core biopsy. Pathology 2001;33:449-453.

$\checkmark 9$ Pisano ED, Fajardo LL, Tsimikas J, Sneige N, Frable WJ, Gatsonis CA, Evans WP, Tocino I, McNeil BJ: Rate of insufficient samples for fineneedle aspiration for nonpalpable breast lesions in a multicenter clinical trial: the radiologic diagnostic oncology group 5 study. The RDOG5 investigators. Cancer 1998;82:679-688.

10 O'Flynn EA, Wilson AR, Michell MJ: Imageguided breast biopsy: state-of-the-art. Clin Radiol 2010;65:259-270.

11 Parker SH, Burbank F, Jackman RJ, Aucreman CJ, Cardenosa G, Cink TM, Coscia JL, Jr., Eklund GW, Evans WP 3rd, Garver PR, et al.: Percutaneous large-core breast biopsy: a multi-institutional study. Radiology 1994;193:359-364.

12 Verkooijen HM: Diagnostic accuracy of stereotactic large-core needle biopsy for nonpalpable breast disease: results of a multicenter prospective study with $95 \%$ surgical confirmation. Int J Cancer 2002;99:853-859.

13 Britton PD, Flower CD, Freeman AH, Sinnatamby R, Warren R, Goddard MJ, Wight DG, Bobrow L: Changing to core biopsy in an NHS breast screening unit. Clin Radiol 1997;52:764-767.

14 Schulz-Wendtland R, Kramer S, Lang N, Bautz W: Ultrasonic guided microbiopsy in mammary diagnosis: indications, technique and results. Anticancer Res 1998;18:2145-2146.

15 Philpotts LE, Shaheen NA, Carter D, Lange RC, Lee $\mathrm{CH}$ : Comparison of rebiopsy rates after stereotactic core needle biopsy of the breast with 11-gauge vacuum suction probe versus 14-gauge needle and automatic gun. AJR 1999;172:683-687.
Jackman RJ, Rodriguez-Soto J: Breast microcalcifications: retrieval failure at prone stereotactic core and vacuum breast biopsy--frequency, causes, and outcome. Radiology 2006;239:61-70.

17 Schueller G, Jaromi S, Ponhold L, Fuchsjaeger M, Memarsadeghi M, Rudas M, Weber M, Liberman L, Helbich TH: US-guided 14-gauge core-needle breast biopsy: results of a validation study in 1,352 cases. Radiology 2008;248:406-413.

18 Dillon MF, Hill AD, Quinn CM, O’Doherty A, McDermott EW, O'Higgins N: The accuracy of ultrasound, stereotactic, and clinical core biopsies in the diagnosis of breast cancer, with an analysis of false-negative cases. Ann Surg 2005;242:701-707.

19 Meyer JE, Smith DN, DiPiro PJ, Denison CM, Frenna TH, Harvey SC, Ko WD: Stereotactic breast biopsy of clustered microcalcifications with a directional, vacuum-assisted device. Radiology 1997;204:575-576.

20 Helbich TH, Matzek W, Fuchsjäger MH: Stereotactic and ultrasound-guided breast biopsy. Eur Radiol 2004;14:383-393.

21 Burbank F, Parker SH, Fogarty TJ: Stereotactic breast biopsy: improved tissue harvesting with the mammotome. Am Surg 1996:738-744.

22 Bagnall MJ, Evans AJ, Wilson AR, Burrell H, Pinder SE, Ellis IO: When have mammographic calcifications been adequately sampled at needle core biopsy? Clin Radiol 2000;55:548-553.

23 Liberman L, Smolkin JH, Dershaw DD, Morris EA, Abramson AF, Rosen PP: Calcification retrieval at stereotactic, 11-gauge, directional, vacuum-assisted breast biopsy. Radiology 1998;208:251-260.

24 Stomper PC, Margolin FR: Ductal carcinoma in situ: the mammographer's perspective. AJR 1994;162:585-591.

25 Kettritz U, Morack G, Decker T: Stereotactic vacuum-assisted breast biopsies in 500 women with microcalcifications: radiological and pathological correlations. Eur J Radiol 2005;55:270-276.

26 Kettritz U, Rotter K, Schreer I, Murauer M, SchulzWendtland R, Peter D, Heywang-Kobrunner SH: Stereotactic vacuum-assisted breast biopsy in 2,874 patients. Cancer 2004;100:245-251.

27 Parker SH, Klaus AJ: Performing a breast biopsy with a directional, vacuum-assisted biopsy instrument. Radiographics 1997;17:1233-1252.

28 Heywang-Kobrunner SH, Schreer I, Decker T, Böcker W: Interdisciplinary consensus on the use and technique of vacuum assisted stereotactic breast biopsy. Eur J Radiol 2003;47:232-236.

29 Heywang-Kobrunner SH, Heinig A, Hellerhoff K, Holzhausen HJ, Nahrig J: Use of ultrasoundguided percutaneous vacuum-assisted breast biopsy for selected difficult indications. Breast $\mathbf{J}$ 2009; 15:348-356.

30 Lee JM, Kaplan JB, Murray MP, Liberman L: Complete excision of the MRI target lesion at MRI-guided vacuum-assisted biopsy of breast cancer. AJR 2008;191:1198-1202.

31 Perlet C, Heywang-Kobrunner SH, Heinig A, Sittek H, Casselman J, Anderson I, Taourel P: Magnetic resonance-guided, vacuum-assisted breast biopsy: results from a European multicenter study of 538 lesions. Cancer 2006;106:982-990.

32 Hahn M, Okamgba S, Scheler P, Freidel K, Hoffmann G, Kraemer B, Wallwiener D, KrainickStrobel U: Vacuum-assisted breast biopsy: a comparison of 11-gauge and 8-gauge needles in benign breast disease. World J Surg Oncol 2008;6:51.
3 Thurley P, Evans A, Hamilton L, James J, Wilson R: Patient satisfaction and efficacy of vacuum-assisted excision biopsy of fibroadenomas. Clin Radiol 2009;64:381-385.

34 Penco S, Rizzo S, Bozzini AC, Latronico A, Menna $\mathrm{S}$, Cassano E, Bellomi M: Stereotactic vacuum-assisted breast biopsy is not a therapeutic procedure even when all mammographically found calcifications are removed: analysis of 4,086 procedures. AJR 2010;195:1255-1260.

35 Sie A, Bryan DC, Gaines V, Killebrew LK, Kim CH, Morrison CC, Poller WR, Romilly AP, Schilling K, Sung JH: Multicenter evaluation of the breast lesion excision system, a percutaneous, vacuum-assisted, intact-specimen breast biopsy device. Cancer 2006;107:945-949.

36 Smathers RL: Advanced breast biopsy instrumentation device: percentages of lesion and surrounding tissue removed. AJR 2000;175:801-803.

37 Doridot V, Meunier M, El Khoury C, Nos C, Vincent-Salomon A, Sigal-Zafrani B, Clough KB: Stereotactic radioguided surgery by SiteSelect for subclinical mammographic lesions. Ann Surg Oncol 2005;12:181-188.

38 Houssami N, Ciatto S, Bilous M, Vezzosi V, Bianchi S: Borderline breast core needle histology: predictive values for malignancy in lesions of uncertain malignant potential (b3). Br J Cancer 2007;96:1253-1257.

39 Eby PR, Ochsner JE, DeMartini WB, Allison KH, Peacock S, Lehman CD: Frequency and upgrade rates of atypical ductal hyperplasia diagnosed at stereotactic vacuum-assisted breast biopsy: 9-versus 11-gauge. AJR 2009;192:229-234.

40 Kohr JR, Eby PR, Allison KH, DeMartini WB, Gutierrez RL, Peacock S, Lehman CD: Risk of upgrade of atypical ductal hyperplasia after stereotactic breast biopsy: effects of number of foci and complete removal of calcifications. Radiology 2010;255:723-730.

41 Maxwell AJ: Ultrasound-guided vacuum-assisted excision of breast papillomas: review of 6-years experience. Clin Radiol 2009;64:801-806.

42 Tennant SL, Evans A, Hamilton LJ, James J, Lee AH, Hodi Z, Ellis IO, Rakha EA, Wilson AR: Vacuum-assisted excision of breast lesions of uncertain malignant potential (B3) - an alternative to surgery in selected cases. Breast (Edinburgh, Scotland) 2008;17:546-549.

43 Carder PJ, Khan T, Burrows P, Sharma N: Large volume 'mammotome' biopsy may reduce the need for diagnostic surgery in papillary lesions of the breast. J Clin Pathol 2008;61:928-933.

44 Brenner RJ, Jackman RJ, Parker SH, Evans WP 3rd, Philpotts L, Deutch BM, Lechner MC, Lehrer D, Sylvan P, Hunt R, Adler SJ, Forcier N: Percutaneous core needle biopsy of radial scars of the breast: when is excision necessary? AJR 2002;179:1179-1184.

45 Becker L, Trop I, David J, Latour M, OuimetOliva D, Gaboury L, Lalonde L: Management of radial scars found at percutaneous breast biopsy. Can Assoc Radiol J 2006;57:72-78.

46 Rajan S, Wason AM, Carder PJ: Conservative management of screen-detected radial scars: role of mammotome excision. J Clin Pathol 2011;64:65-68.

47 Linda A, Zuiani C, Furlan A, Londero V, Girometti R, Machin P, Bazzocchi M: Radial scars without atypia diagnosed at imaging-guided needle biopsy: how often is associated malignancy found at subsequent surgical excision, and do mammography and sonography predict which lesions are malignant? AJR 2010;194:1146-1151. 